\title{
NEED Northern European Enclosure Dam
}

To protect fifteen northern European countries against sea level rise, a highly ambitious plan was put forward to build massive sea dams across the North Sea and the English Channel, which will cut off the North Sea from the rest of the Atlantic Ocean.
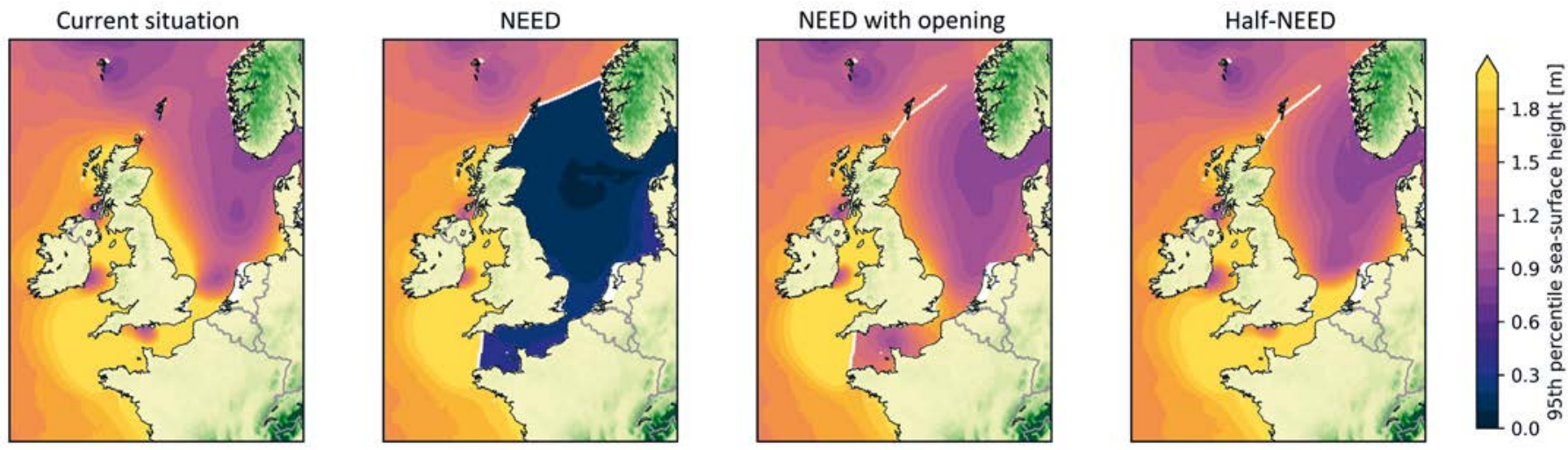

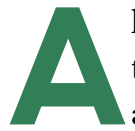

lthough we desperately want this plan [1] never to become a reality, future projections of high-end sea level rise (SLR) of over 7 $\mathrm{m}$ in 2300 may warrant a solution of this proportion [2]. Considering the high risks of such scenarios and the long lead time for adaptative solutions to be put in place[3][4], it is essential to plan ahead for solutions in case the high-end scenarios do become a reality.

The costs to construct NEED are estimated at about $€ 250$ - $€ 500$ billion. Spread out over 20 years and over the 15 protected countries, it would cost less than $0.2 \%$ of their GDP and could be a cost-effective solution. Now, after a year since publication of the idea, we have not heard from an expert who claims NEED cannot be constructed. This includes the requirement to

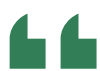

We emphasise that NEED is symptomatic treatment of the consequences of climate change. The best solution remains to intensify climate change mitigation efforts now. $\square$
A Preliminary results show the sea surface height exceeded once every 20 years, or less. Obtained using a numerical simulation [1] Half-NEED reduces the amplitude significantly in some regions and could maybe be effective. pump out $\pm 40.000 \mathrm{~m}^{3} \mathrm{~s}^{-1}$ of river discharge into the Atlantic. Yet, there are concerns about the implementation time and the impact of NEED on ecosystems, the maritime shipping industry and terrorist threat. The latter however is worse for coastal dikes, as breaking NEED will first flood a huge catchment area that can delay flooding of coastal cities by months, whereas breaking coastal dikes will cause cities to flood within hours.

Recently, Engineers Wim Uijttewaal and Bas Jonkman of Delft University in the Netherlands suggested to start by building only half of the enclosure between Scotland and Norway and remove the part between France and England entirely. Although this doesn't protect against the global-mean SLR itself, preliminary results (see figure) do suggest this could reduce the sea level height extremes with more than 1 meter locally, thanks to a damping of tidal amplitudes and storm surges. "Half-NEED" could thus reduce sea level extremes and therefore allow for some global-mean SLR in order to maintain the same protection standard of our coastal dikes. If the incremental plan of "Half-NEED" works, it provides protection, while leaving the ecosystems and shipping industry relatively untouched. And if all fails, we can still enclose the whole basin.

We emphasise that NEED is symptomatic treatment of the consequences of climate change. The best solution remains to intensify climate change mitigation efforts now. NEED however, is a powerful image capturing the possible consequences of climate change and is therefore mostly presented as a warning. Not a solution we should aim for, but a reality we should avoid and to be sure, investigate.

- Sjoerd Groeskamp, NIOZ Royal Netherlands Institute for Sea Research, Texel, Netherlands

- Joakim Kjellsson, GEOMAR Helmholtz Centre for Ocean Research Kiel

\section{References}

[1] S. Groeskamp and J. Kjellsson, NEED: The Northern European Enclosure Dam for if Climate Change Mitigation Fails. Bull. Am. Meteorol. Soc.101, E1174-E1189

[2] J. Hinkel et al., The ability of societies to adapt to twenty-first-century sea-level rise, Nat. Clim. Chang. 1 (2018).

[3] M. Haasnoot and Coauthors, : Adaptation to uncertain sea-level rise; how uncertainty in Antarctic mass-loss impacts the coastal adaptation strategy of the Netherlands. Environ. Res. Lett.15, 034007 (2020). 